\title{
FNAC Diagnosis of Primary Intraosseous Squamous Cell Carcinoma Mandible: A Rare Case Report
}

\author{
Dr. Deepika Wadhera ${ }^{1}$, Dr. Simranjeet Kaur ${ }^{2 *}$, Dr. Prem Singh ${ }^{3}$, Dr. Shiv Pankaj Khanna ${ }^{3}$ \\ ${ }^{1}$ Assistant Professor, Department of Pathology, Maharishi Markandeshwar Institute of Medical Sciences and Research (MMIMSR), \\ Mullana, Ambala, State-Haryana 133207, India \\ ${ }^{2} J u n i o r$ Resident, Department of Pathology, Maharishi Markandeshwar Institute of Medical Sciences and Research (MMIMSR), \\ Mullana, Ambala, State-Haryana 133207, India \\ ${ }^{3}$ Professor, Department of Pathology, Maharishi Markandeshwar Institute of Medical Sciences and Research (MMIMSR), Mullana, \\ Ambala, State-Haryana 133207, India
}

\author{
DOI: $\underline{10.36348 / \text { sjpm.2022.v07i01.007 }}$ \\ | Received: 13.12.2021 | Accepted: 17.01.2022 | Published: 29.01.2022 \\ *Corresponding author: Dr. Simranjeet Kaur \\ Junior Resident, Department of Pathology, Maharishi Markandeshwar Institute of Medical Sciences and Research (MMIMSR), \\ Mullana, Ambala, State-Haryana 133207, India
}

\section{Abstract}

Primary intraosseous squamous cell carcinoma of jaw is a rare tumour. It arises from the lining of an odontogenic cyst or de novo from postulated odontogenic cell rests and is rarely diagnosed by FNAC. The primary intraosseous carcinoma of squamous cell origin is very infrequent and only few cases are reported in available literature. The following case report describes a case of primary intraosseous squamous cell carcinoma of mandible in a 45 year old male patient with emphasis on cytological features. The main purpose is to highlight diagnostic significance of FNAC for rapid and accurate diagnosis of lesions of mandible and unusual clinical presentation.

Keywords: FNAC, Mandible, Primary intraosseous squamous cell carcinoma.

Copyright $(02022$ The Author(s): This is an open-access article distributed under the terms of the Creative Commons Attribution 4.0 International License (CC BY-NC 4.0) which permits unrestricted use, distribution, and reproduction in any medium for non-commercial use provided the original author and source are credited.

\section{INTRODUCTION}

A primary intraosseous squamous cell carcinoma (PIOSCC) is a squamous cell carcinoma (SCC) which arises within the jaw bones with no initial connection with the oral mucous membrane [1]. Loos in 1913, first described PIOSCC as a central epidermoid carcinoma of the jaw [2]. In 1972, the WHO and Pindborg approved the term "Primary intraosseous odontogenic carcinoma (PIOC) [3]. Lining of odontogenic cyst may transform into SCC, besides other benign and malignant odontogenic tumours. Residual cyst is considered the common cyst followed by dentigerous cyst as leading cause of SCC. Our purpose of this article is to represent the clinical, radiological and microscopic features of PIOSCC. This case report is the addition to the very few cases of PIOSCC in the literature.

\section{CASE REPORT}

A 46 year old male patient reported to our institute with the chief complaints of pain and numbness in the left lower jaw since 3 months. The pain was aggravated while chewing food. Subsequently, the patient developed pus discharge in the same region and underwent medical treatment for the same. The patient had a history of bidi smoking (10 bidis per day) since last 15 years.

Local extraoral examination revealed diffuse bony hard swelling in the left mandibular ramus region causing facial asymmetry. Left submandibular lymph node was palpable measuring $1 \times 0.5 \mathrm{~cm}$, which was tender, and not fixed to underlying structures on palpation.

On intraoral examination, growth was present in the socket of 36 which was erythematous and covered with slough giving granular appearance. Also pus discharge was present (Figure 1).

Orthopantomogram shows evidence of missing teeth with respect to 36 and lytic bone lesion in $36 \& 37$ region (Figure 2). 
The patient was then advised contrast enhanced computed tomography (CECT) face which revealed lytic lesion in body of mandible area left side extending till alveolar part with minimal surrounding soft tissue involving the mucosa. Also few lymph nodes in left submandibular region were appreciated (Figure $3)$.

A USG guided FNAC from left body region of mandible was performed. A 22 gauge needle was introduced and aspirate was taken under all aseptic precautions. Smears were prepared, air dried and alcohol fixed and were subjected to further staining. On microscopic examination, the smears were cellular and showed atypical squamous cells lying in clusters as well as singly. Cells were medium to large with hyperchromatic nuclei, some showing prominent nucleoli. Scattered in between seen few osteoclastic giant cells. Many tadpole and fibre cells were seen. Cytological features were suggestive of Squamous Cell Carcinoma. Lymph node aspirate shows reactive changes (Figure $4 \mathrm{~A}-\mathrm{D}$ ).

Our diagnosis was confirmed as Well differentiated Squamous Cell Carcinoma on histopathology of curettage tissue from lytic lesion.

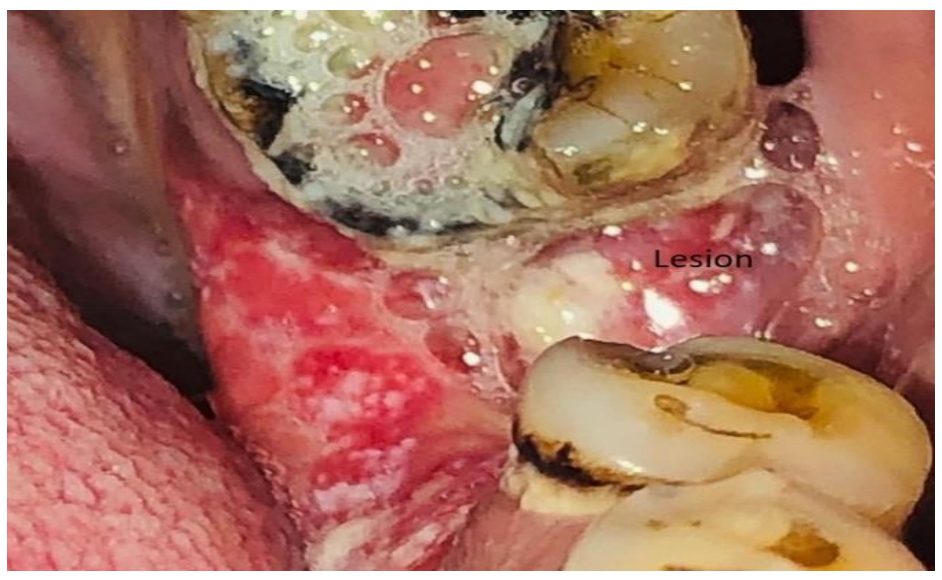

Figure 1: Intraoral photograph showing lesion at the site of FNAC in the mandible

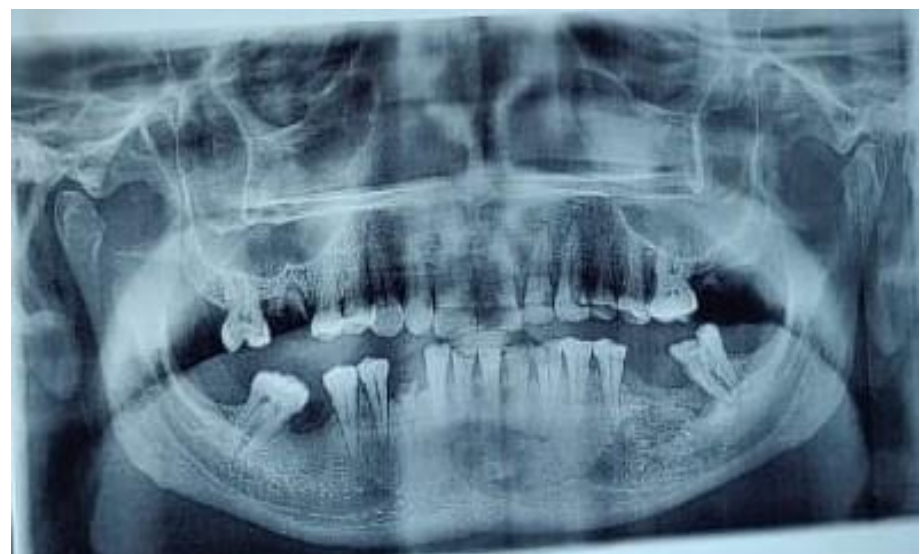

Figure 2: Orthopantomogram showing lytic lesion in region 36 \& 37 


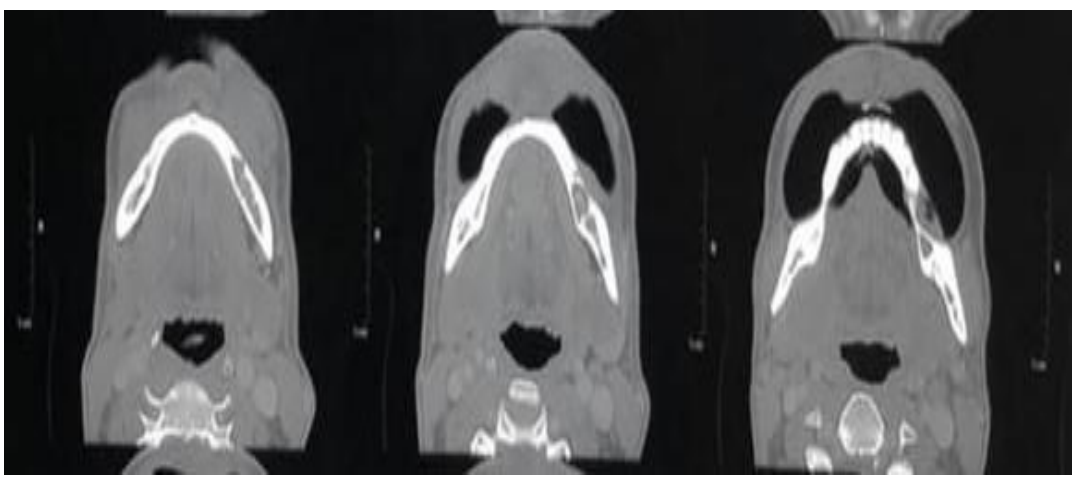

Figure 3: CECT showing lytic lesion in body of mandible left side
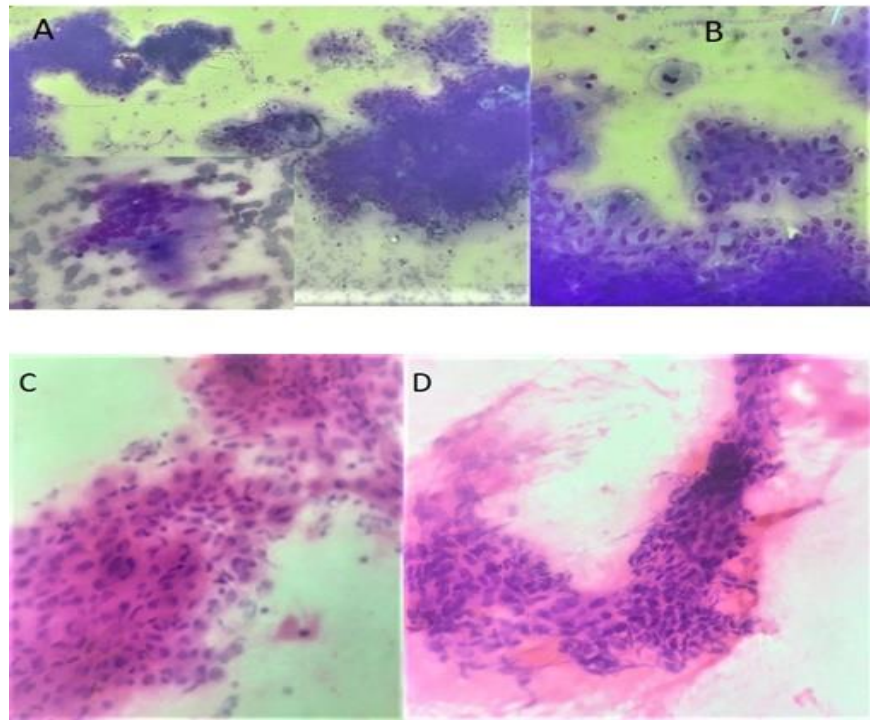

Figure 4: SCC. A \& B- Smear shows atypical squamous cells arranged in clusters and singly scattered cells. Inset A showsOsteoclastic like giant cells. L \& G X 400; C \& D- Smear showing significant atypia. H \& E X 400

\section{DISCUSSION}

PIOSCC is a rare odontogenic carcinoma. ${ }^{[4]}$ Loos was the first to describe the tumor in $1913 .{ }^{[2]}$ In 1972, WHO suggested the term primary intraosseous carcinoma and classified the lesion as an odontogenic carcinoma. ${ }^{[3]}$ Adults in sixth to seventh decade are mainly involved with male to female ratio of 2:1.Posterior mandible is the most common site involved. ${ }^{[5]}$

However, in 2005 according to the new WHO classification, PIOSCC replaced the old terms and was sub classified as a:

- Solid tumour that invades marrow spaces and induces bone resorption.

- $\quad$ SCC arising from an OKC lining or carcinoma arising in other odontogenic cysts

- $\quad$ SCC associated with benign epithelial odontogenic tumours [1].

Primary introsseous squamous cell carcinoma (PIOSCC) is a central jaw carcinoma which is derived from odontogenic epithelial remnants. Thereby according to the latest classification, PIOC arising de novo (keratinizing type) is classified as PIOSCC
(Primary intraosseous squamous cell carcinoma) which is the final diagnosis given in our case [6].

Age and site in our case corroborated in the study by Thomas et al., [7]. The pathogenesis of this lesion is presently unknown. In 2003, gardner and Yu et al., [8] suggested that the long standing chronic inflammation has also been a possible predisposing factor. Our patient had history of tobacco smoking which must be the triggering factor by causing oxidative stress.

Pain and swelling are the common clinical features. In the study conducted by Thomas et al., pain was the most common feature in $54.8 \%$ patients followed by swelling of the jaw in $51.65 \%$ and sensory disturbances in $16.1 \%$ which is similar to this case study in which, pain, swelling, and paresthesia were seen [7].

Yamada et al., in the research of clinicpathological study of five cases of PIOC found three cases of well-differentiated carcinoma, and one moderately differentiated carcinoma [9]. Also in this 
Deepika Wadhera et al; Saudi J Pathol Microbiol, Jan, 2022; 7(1): 35-38

case, the tumour was a well differentiated keratinizing squamous cell carcinoma.

Role and importance of FNAC for diagnosis was highlighted by $\mathrm{R}$ desai et al., in their study [10]. The current management of PIOC is wide surgical resection. For the lesions that cannot be surgically controlled, other treatment modalities, such as radiotherapy or chemotherapy, should be considered. The prognosis is generally poor [7].

\section{CONCLUSION}

Whenever the patient presents with pain and swelling along with intraosseous lesions, one should consider the possibility of intraosseous carcinomas. FNAC diagnosis of this carcinoma is rare and the present case report is to highlight its diagnostic significance in such cases. The FNAC has an extra edge in such lesions due to its simple, easy, rapid and less invasive and cost effective nature.

\section{REFERENCES}

1. Tamgadge, S., Tamgadge, A., Modak, N., \& Bhalerao, S. (2013). Primary intraosseous squamous cell carcinoma arising from an odontogenic keratocyst: a case report and literature review. Ecancermedicalscience, 7, 316.

2. Loos, D. (1913). Central epidermoid carcinoma of the jaws. Dtsch Mscnr Zahnhelic, 31, 308-310. Quoted in: Morrison, R., \& Deeley, T. J. (1962). Intra-alveolar carcinoma of the jaw. Treatment by supervoltage radiotherapy. The British journal of radiology, 35(413), 321-326.

3. Pindborg, J. J., Kramer, I. R. H., \& Torloni, H. (1991). Histological Typing of Odontogenic
Tumours, Jaw Cysts, and Allied Lesions. $1^{\text {st }}$ ed. Geneva: World Health Organization; p. 35-36.

4. Reichart, P. A., \& Philipsen, H. P. (2004). Odontogenic Tumors and Allied Lesions. London: Quintessence Publishing Co., Ltd.; P. 205-25.

5. Van Wyk, C. W., Padayachee, A., Nortje, C. J., \& Von Der Heyden, U. (1987). Primary intraosseous carcinoma involving the anterior mandible. British Journal of Oral and Maxillofacial Surgery, 25(5), 427-432.

6. Eversole, L. R., Sabes, W. R., \& Rovin, S. (1975). Aggressive growth and neoplastic potential of odontogenic cysts. With special reference to central epidermoid and mucoepidermoid carcinomas. Cancer, 35(1), 270-282.

7. Thomas, G., Pandey, M., Mathew, A., Abraham, E. K., Francis, A., Somanathan, T., ... \& Nair, M. K. (2001). Primary intraosseous carcinoma of the jaw: pooled analysis of world literature and report of two new cases. International journal of oral and maxillofacial surgery, 30(4), 349-355.

8. Yu, J. J., Hwang, E. H., Lee, S. R., \& Choi, J. H. (2003). Squamous cell carcinoma arising in an odontogenic cyst. Imaging Science in Dentistry, 33(4), 235-238.

9. Yamada, T., Ueno, T., Moritani, N., Mishima, K., Hirata, A., \& Matsumura, T. (2009). Primary intraosseous squamous cell carcinomas: five new clinicopathologic case studies. Journal of CranioMaxillofacial Surgery, 37(8), 448-453.

10. Desai, S. R., Mane, A. M., Kumbhar, S., Bonde, V., \& Sonawane, R. L. (2017). Cytodiagnosis of primary intraosseous squamous cell carcinoma of left mandible with unusual finding. Archives of Cytology and Histopathology Research, 2(1), 2122. 